\title{
EOLATION DYNAMICS IN THE SHORE OF ARTIFICIALLY IMPOUNDED BODIES (BY THE EXAMPLE OF BRATSK WATER RESERVOIR, RUSSIA)
}

\author{
Khak V. A. ${ }^{1}$, Kozyreva E. A. ${ }^{1}$, and Trzhcinsky Yu. B. ${ }^{1}$ \\ ${ }^{\prime}$ Institute of the Earth's Crust Academy of Sciences Siberian Branch, Laboratory of engineering \\ geology and geoecology,Lermontov Street 128,664033 Irkutsk, Russia, khak@crust.irk.ru, \\ kozireva@crust.irk.ru,trzhcin@crust.irk.ru
}

\begin{abstract}
The process of eolation in the near-shore area of the Bratsk water reservoir results in the landscape changes and may lead to abrasion process activation. The eolation dynamics factors are water level and wind conditions. The eolation shows a cyclical pattern that is primarily related to the duration of low stand of level. The eolation processes that differ in sedimentation rate, water level and morphology of eolian relief forms ranging from mere sand blowing to travelling dunes have been phased in studies of the sections of dune sand deposits. The topography model of index plot Rassvet that makes it possible to scale the process of eolation and to know some regular trends and mechanisms of its development has been constructed as result of eolation dynamics research.
\end{abstract}

Key words: deflation, dune complex, sedimentation phase, surface topography model.

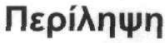

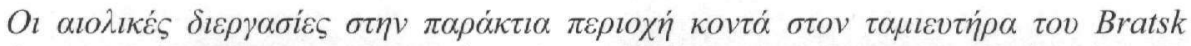

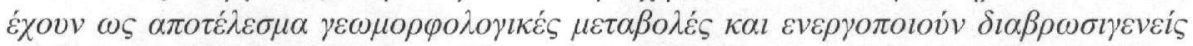

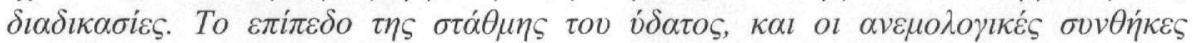

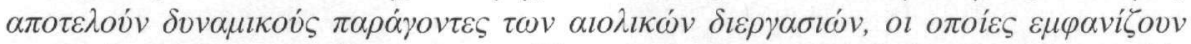

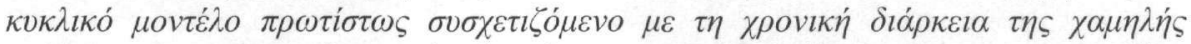

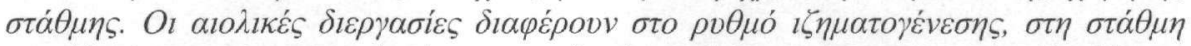

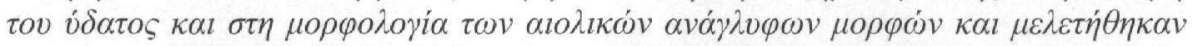

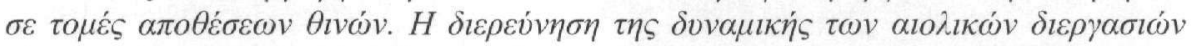

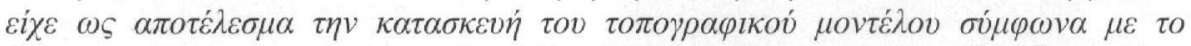

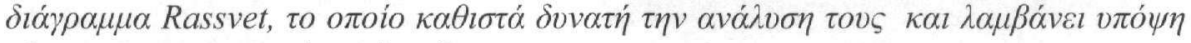

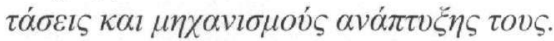

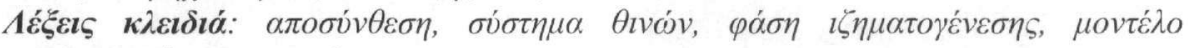

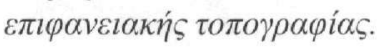

\section{Introduction}

The formation of large natural-technical systems of water reservoirs inevitably involves irreversible environment modification. The water reservoirs are an important anthropogenic factor 
activating many exogenous geological processes that are detrimental to near-shore areas. The engineering-geological study of the territories coming under the influence of the Angara water reservoirs that have been in operation for many years is one of the "hottest" areas in current research as the adjacent lands become more and more populated and used for different economic purposes. The study of dynamic changes inside the shore-based geosystems, and revelation and analysis of their regular trends are the main criterion of estimation of systematic condition of water reservoir (Ivanov and Trzhtsinsky 2001).

The Bratsk reservoir made in 1961-1967 in the valleys of Angara, Oka and Iya Rivers (south of the East Siberia, to the west of Lake Baikal) is one of the largest artificially impounded bodies in the world. It south-north extension is $600 \mathrm{~km}$, water table area is $5470 \mathrm{~km}^{2}$, and water mass is $170 \mathrm{~km}^{3}$. A feature of the water reservoir is an irregular shoreline caused by landforms and geological structure of the ground. The total shoreline is as long as $6013 \mathrm{~km}$ (Ovchinnikov et al. 1999).

Processes like landslides, karst, abrasion, erosion and eolation are progressing rapidly in the shore of Bratsk reservoir. Eolation has been the subject of this study. Wind erosion that is a contributory factor for sand blowing results in occurrence of sizable eolian relief forms and in their propagation and encroachment upon woodland, steppes, cultivated land, settlements etc. These conditions significantly affect the landform, from land topography to plant communities. The eolian relief forms are characterized by sparse vegetation, with little or no herb in places. Besides, the eolation confined to the shores of reservoirs does much to shape the shore. The eolation evacuation and accumulation of sand beyond an emerged shoal upsets the drift balance. In the beach drift, there is a deficit of sand involved in shoal formation, leading to shoal flattening that may subsequently activate abrasion.

\section{Materials and Methods}

The work has been done on a basis of the analysis of the data obtained by the author during the 2000-2006 fieldwork and processing of the previous cartographic documents and aerial photographs. The index plots have been pre-selected on the basis of eolation development and different actions of eolation.

The study of granulometric composition of eolian deposits has been made with a standard grainsize analysis of the selected samples and statistical post-processing of results by the method of V.P. Zenkovich (1962).

The data used for three-dimensional modeling of index plots were obtained in summer 2006 with the help of current satellite geodetic facilities, namely, the GPS measuring procedure was followed in kinematic mode. This procedure enables fast and efficient obtaining of data for surface topography modeling with accuracy to the first centimeters. Two GPS receivers and two antennas were used in the kinematic observations. The main receiver was left in place whereas another one was removed through a number of sites. In these sites short-period observations were made during 0.5 minutes. All baselines are measured in reference to the main (static) receiver. The kinematic observation procedural standards are that all receivers pick up signals at least from four GPS satellites at any time.

\section{Process activating factors}

By geological structure of the land adjacent to the reservoir, the shore sand floods appear to be confined to strictly localized areas. Processes of eolation are progressing rapidly within the Bratsk reservoir on emerged shoals composed of fine-grained and medium-grained sand drifts. The reason has to do with the erosion of terraces in the heads of Angara, Oka and Iya valleys that are composed of sandy-loam and sandy deposits and with old eolian relief forms confined to extensive parts of the river valleys. To a smaller extent eolation acts on shoals derived from erosion of 
sandstones of the Ordovician Mamyrsky subformation, composed of medium-grained and coarsegrained sand drifts (Ovchinnikov 1998). The eolian fields are most pronounced in the Dolonovsky and Kaltuksky extensions along the Okinsky Bay, in the heads of Angara, Oka and Iya reaches, and on the left bank of Zayarsk extension along the Angara water area (Logatchev et al. 1964).

Of the variety of factors, which affect eolation, the level and wind conditions seem to hold the lead. The emerged shoal composed of wind-stirred layers varies in width with the amplitude of water level fluctuations. The eolation shows a cyclical pattern that is primarily related to the duration of low stand of level. In annual change of the level the watermarks are the lowest in spring and summer period when the longest wind speed duration favors the eolation.

The Bratsk water reservoir is over-years storage, with the amplitude of fluctuations in the drawdown level ranging up to 10 meters. In multiyear change of the level of the Bratsk water reservoir they have previously recognized the high-stand periods (2-6 years), in which stream-bank erosion is progressing with the accumulation of material on the shoal, and low-stand periods, in which this shoal is emerged for $200-550 \mathrm{~m}$ (Vika et al. 2000).

A feature of wind conditions in the head of Angarsk water area of the Bratsk reservoir where eolation is being studied is the prevailing winds blow northwest, west and southwest that are more than one-half the frequency of wind directions. In this case consideration must be given to the orientation of the shores where eolation is progressing most rapidly. The shore of Nelkhai index plot, described in detail below, is oriented to the west; because of this, the sand is stirred here by all three winds prevailing, of which the most frequent is the west one (120-125 hours per month). On Rassvet index plot with the northward orientation of shores the prevailing winds blow north (30-35 hours per month) and northwest (80-100 hours per month) (Khak 2003b).

\section{Investigations on index plots}

The shore of Bratsk water reservoir has been prone to eolation since its impounding in 1967. Today's problems of eolation associated with other exogenous geological processes are studied on two index plots at the head of the water reservoir.

Rassvet plot is located on the very borderline between the proper Bratsk water reservoir and Osinsky Bay. The plot shoreline is shaped like a convex bow extending for $5.5 \mathrm{~km}$ west-to-east. The shore formation covers a $3-8^{\circ}$ gradient slope. The western shore of the plot is composed of the Verkholensky aleurolite and argillite rock series of the Cambrian and overlain by loose sedimentary cover $0.2-1.0-\mathrm{m}$ in thickness. The beach scarps have the maximum height there and may be as high as $1-15 \mathrm{~m}$. The shore deposits in the center of the plot are represented by sandy loams with interlayered fine-grained dust sands and those in the east of the plot are composed of medium-grained sand. The height of the beach scarps lowers to $1.5-2.0 \mathrm{~m}$ to the east. The variability in geological structure of the shorefaces reflected not only on morphology of the plot but also on developmental character of the plot processes.

The western part of the plot where the emerged shoal is composed of aleurolite (siltstone) and argillite fragmentary material is quite unaffected by eolation. Most of the shore is eolated for $3.5 \mathrm{~km}$ in the eastern and central parts where the shoals are composed of medium-grained, usually fine-graded sandstones and may run as wide as $100-350 \mathrm{~m}$ with the lowest water level in the reservoir. Recognized here are two morphologIcally different zones with defined eolian relief forms.

The first is dune complex zone located in the west of the plot is the outgrowth of the bay separated by a bay-bar that developed in the first years of impounding. The bay-bar that functions as a beach scarp at this part of the shore is partially decomposed by narrow deflation trenches and corridors, formed by the northwest wind in its body, and does not prevent the wind-lifted shoal sand from being carried towards the deeper bay area. The dune complex occupies an area of about $1.5 \mathrm{ha}$; the 
dunes resulting from blowing sand are as high as 1.5-3 and have asymmetrical slopes (Vika et al. 2000).

Various eolian relief forms, from slope topography to areal covers, are typical of the second zone. The beach scarp is sufficiently high there that it is a morphological barrier to an abundant flow of sand. Besides, the shoreface is slightly forested so that eolian relief forms like dunes have not formed. This zone is noted for the relationship of eolation and abrasion (Khak et al. 2005) favored by a widespread occurrence of light-textured soils and grounds, poorly aggregated, with the low or medium content of humus, highly porous, and of small-base exchange capacity. Over an extension of $2.5 \mathrm{~km}$ the beach-scarp area is penetrated by many of small gorges and erosion washouts that have suffusion-subsidence and erosion-suffusion increment mechanism. The erosion relief forms are filled with eolian deposits. The sand blown from the emerged shoal penetrates with the gorge mouth, most often forming the attached ridges near its sides. As this takes place, accumulation in the gorge mouth occurs near the eastern side due to the prevailing winds blow west and northwest whereas an accumulative form at the top of the gorge moves towards the western side. In individual cases a small ridge occurs in bay-bar form in the gorge mouth.

The eolian material moves over a series of small trenches on the edge of the shore to the shoreface where the transverse narrow ridges of the northwestern strike are formed at an angle of $35-40^{\circ}$ to the shore edge. The ridges are $15-20 \mathrm{~m}$ in length on the average, $60-80 \mathrm{~cm}$ in width, and $40 \mathrm{~cm}$ in thickness.

Small negative landforms favorable to the concentration of snowmelt runoff that is followed by disintegration of beach scarps present what is called "corroded" relief formed on old herb-covered eolian deposits. Sand blowing is responsible for the hollows of an area $15-25 \mathrm{~m}^{2}$ and the hummocks, fastened by vegetation that is more tolerant to deflation, remain intact. Common here are eolian sand-filled fractures of shearing type and sheared rock fragments.

Typically the lifetime of eolian formations within erosional forms is short and reduced to one season as in spring they are washed by melt waters and the material that makes up these formations is almost entirely evacuated to an emerged shoal anew, producing the alluvial fans in the process.

The Nelkhai index plot is in the northern part of the peninsular located along the east shore of the reservoir opposite Nelkhai settlement. This plot is extending for $9 \mathrm{~km}$. The shoreface is composed of fine-grained dust sands in the southern and northern parts and of sandy loam with interlayered sand in the middle part. The plot has hummock-and-hollow topography. Shoal morphology on this plot is very typical. The angle of slope of the shoal surface is ranging from $3-5^{\circ}$ in the southern and central parts of the plot to $1-2^{\circ}$ in the northern part of it, and the shoal width therewith varies between $30-70 \mathrm{~m}$ and $350-400 \mathrm{~m}$.

The dune system was formed on the shoreface under the effect of the winds blowing northwest and north. The dune field is $300-350 \mathrm{~m}$ in extension at a width of $50 \mathrm{~m}$. The dunes encroach upon the birch forest in their full extension. They vary in height from 1 to $3 \mathrm{~m}$. The dune slopes are of two types there: windward on the west and leeward on the east, with a steep gradient corresponding to an angle of repose of sands. Behind the dunes, on a slightly forested slope the eolian sand accumulation is no more than $5 \mathrm{~cm}$ thick (Ovchinnikov et al. 1999).

\section{Results and discussion}

With the aim of determining some regular trends of eolian sedimentation six sections have been studied within the dune formations of two index plots. Eolian deposits of the sections are represented by variable-grain size (fine- and medium- grained) and variously colored sand, and some of them are characterized with bedding. Figure 1 shows two engineering-geological sections of dunes of Rassvet and Nelkhai plots with the curves that relate soil grading to section height. One of them, on the forested slope of Nelkhai plot, revealed buried humus horizons. We suggest 
that soil humification is confined to the periods of high water in the reservoir and associated bedrock and soil moistening and more rapid vegetative growth and thus a thick blanket of fallen leaves. This is evident from the layer of half-rotten leaves in the upper section beneath a $5-\mathrm{cm}$ thick layer of sand accumulated over the autumn and spring of 2001-2002.
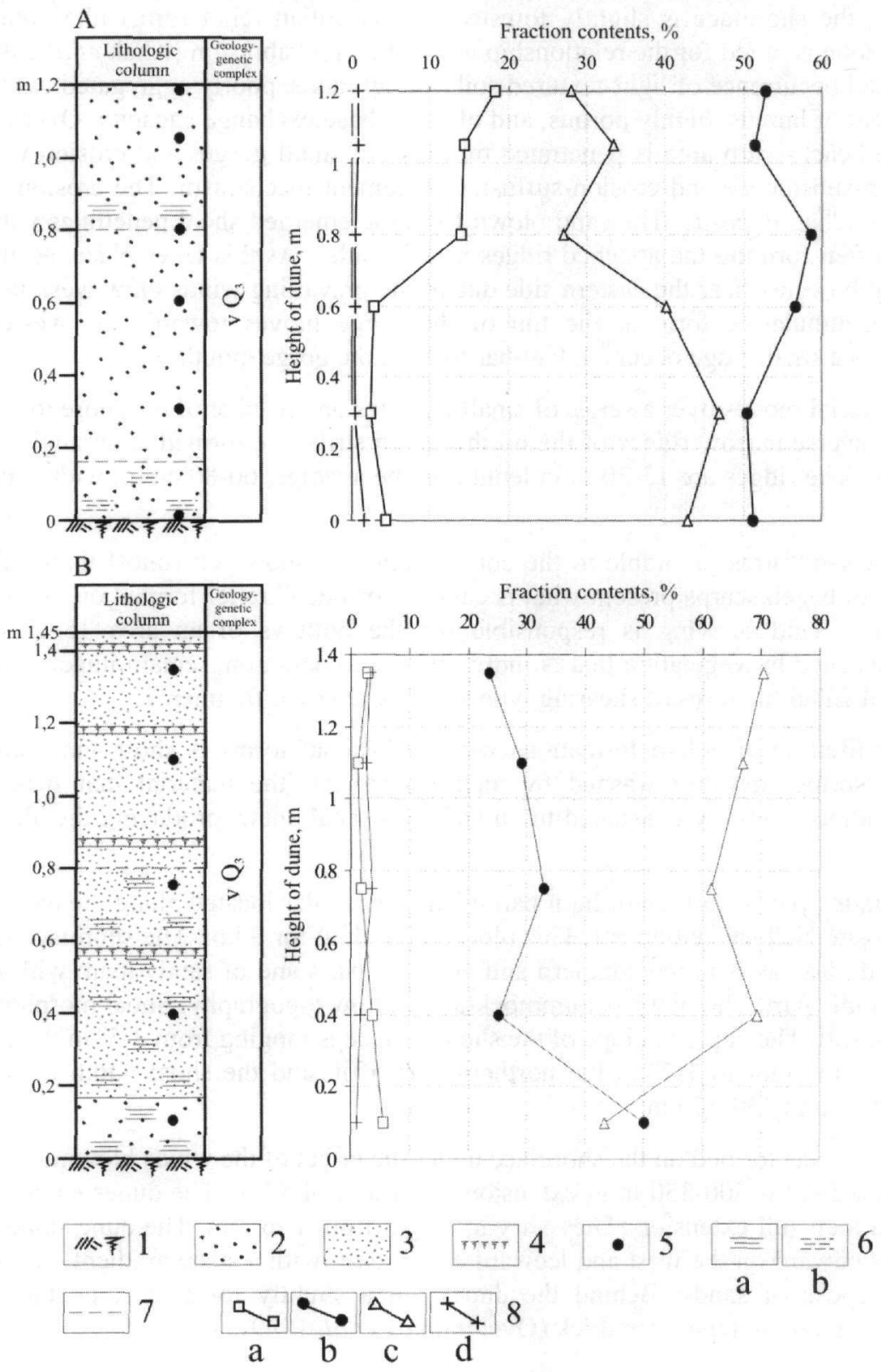

\section{Figure 1 - Engineering-geological sections of dunes of Rassvet and Nelkhai plots}

1 - soil layer; 2 - medium sand; 3 - fine sand; 4 - buried humus horizon; 5 - site of sampling of the disturbed sand structure; 6 - texture characteristics: $\mathrm{a}$ - distinct lamination, $\mathrm{b}$ - indistinct lamination; 7 -delimitation of layers of different texture characteristics; 8 - fraction contents of: a - coarse sand $(>0,5 \mathrm{~mm}), \mathrm{b}-$ medium sand $(0,5-0,25 \mathrm{~mm}), \mathrm{c}-$ fine sand $(0,25-0,1 \mathrm{~mm}), \mathrm{d}-$ fine sand $(<0,1 \mathrm{~mm})$

From detailed study of the section we have come to the following conclusion. The buried humus horizons are clearly defined through the section at 56,86,117 and $140 \mathrm{~cm}$ from the bottom. When 
the obtained data are compared with the variation of reservoir level throughout reservoir period, it is apparent that the formation of humus horizons can be confined to the following time intervals: 1973-1974, 1984-1989, 1994-1995, and 2001 (Khak 2003a). Consequently, 5 principal stages of sedimentation (Fig. 2) and an initial (preparatory) stage of eolation (1967-1968) are recognized. This stage is characterized by some accumulation of sand material near the beach scarps as a result of eolation denudation during the spring-summer period of low water level in the reservoir followed by washing away of sand deposits and slope wash as the level rose to the normal water surface in autumn. By the early 1969 the emerged shoal had enough material for eolation.

The interpretation of aerial photographs of 1969 and 1980 has given the chance to follow dynamics of eolation within the Rassvet plot in the first years of the reservoir operation and to determine the size of the eolated area. The area of eolian massif was $1790 \mathrm{~m}^{2}$ in 1969 and $20306 \mathrm{~m}^{2}$ in 1980 and thereby increased almost eleven times over a period of 11 years. This increase in eolation rate may be confined to the first stage when the rate of eolian sedimentation was also the highest.

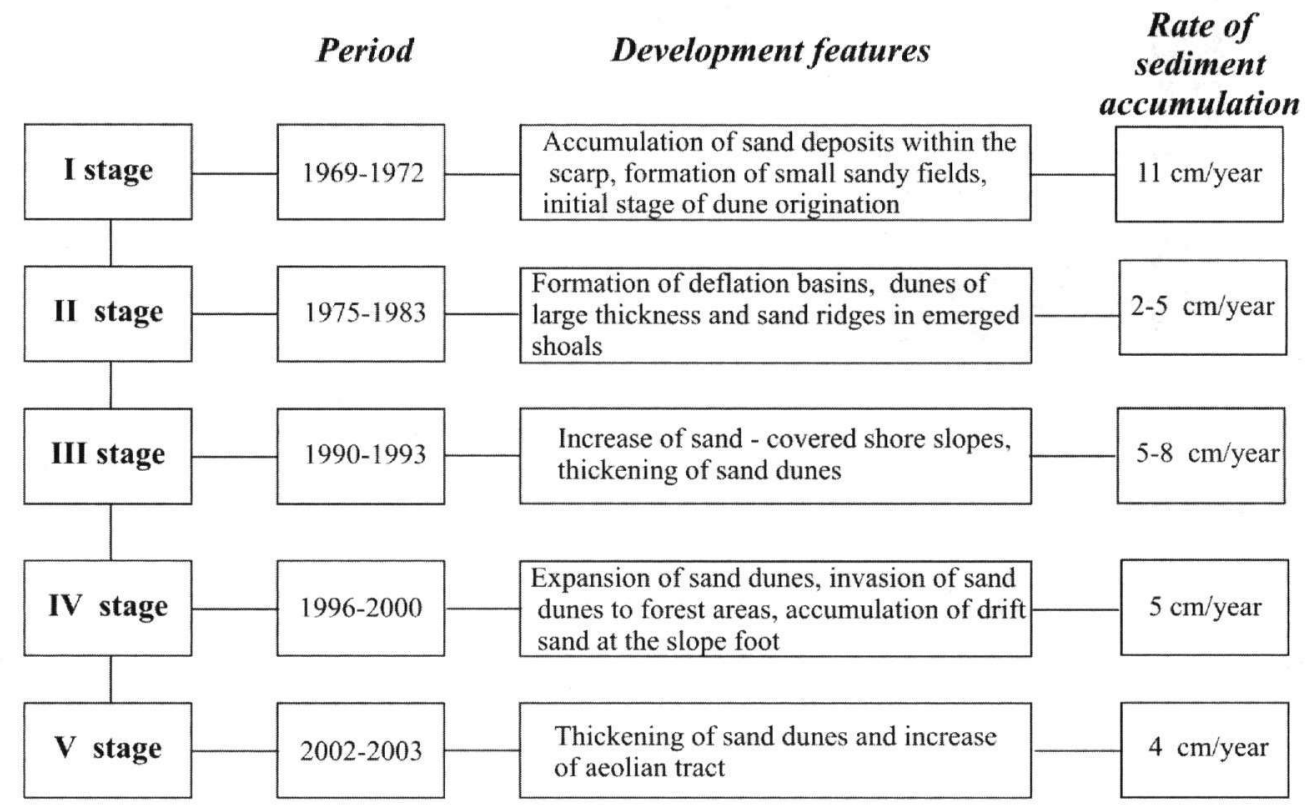

Figure 2 - Chart of stages of eolation

One of the latest results in the study of eolation dynamics is the surface model of the Rassvet index plot constructed from the data on 2006 showing the boundaries observed for the investigated area of eolation and the contoured crest of trenched and eroded beach scarp. Figure 3 presents thedemonstration model, which is only a part of a general working model of the Rassvet plot covering nearly $2-\mathrm{km}$ shore-parallel area. The working model makes it possible to scale geological processes, to determine the size of the affected area, and to know some regular trends and mechanisms of its development. For example, the area of investigated eolian massif is presently estimated as $26727 \mathrm{~m}^{2}$. The extension of the area is due to sand deposit supply to the shoreface from the shoal. It is favored by both near-slope eolian relief forms, which level the beach scarp and offer a peculiar kind of launching pad for inland flow of sand, and erosional forms that are acting as deflationary corridors. (As illustrated in Fig. 3, the eolian fields partially copy the contour of the crest of eroded beach scarp). It is not surprising, then, that under favorable conditions of both eolian form strikes and wind directions many of erosion scars and trenches are initially filled with eolian material and can also favor the progress of eolation later on. 

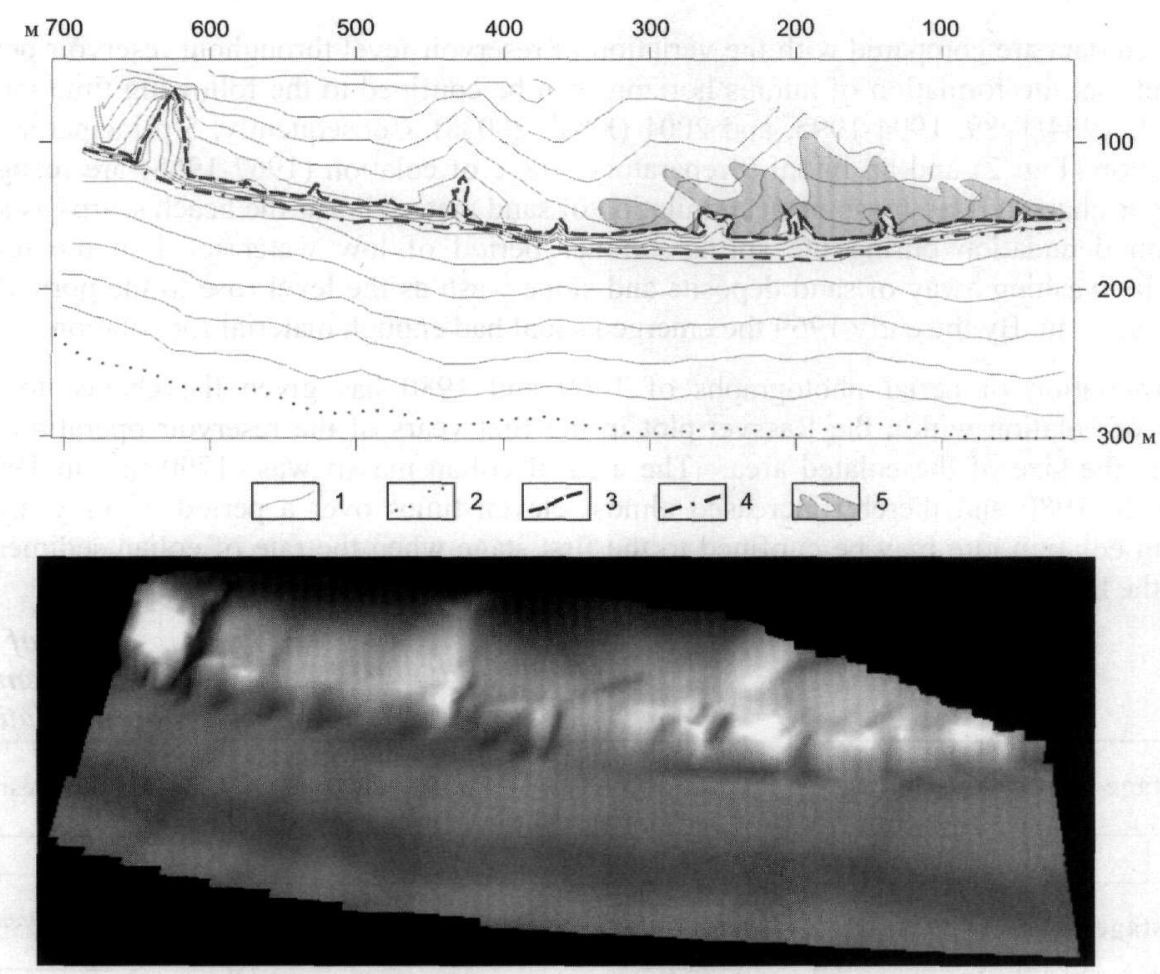

Figure 3-Surface topography model of the investigated area of the eastern part of the shore of the Rassvet plot with symbols of the observed morphological elements and EGP development area boundaries

1 - continuous contours (spaced $1 \mathrm{~m}$ apart); 2 - water line; 3 - crest of the scarp; 4 - foot of the scarp; 5 - eolian massif

Similar works on the generating of the models that carry information concerning exogeodynamic conditions of the investigated area have been done in some of the plots on the shore of the Bratsk reservoir area characterized by rapidly progressing abrasion, erosion, and accumulation. The results of comparative model study of the investigated areas for the last few years will allow us to come to the question of predicting exogenous geological process with interactions.

\section{Acknowledgments}

The work has been done under financial support of RFBR (Project No. 06-05-64392).

\section{References}

Ivanov, I.P., and Trzhtsinsky, Yu.B., 2001. Engineering geodynamics, Nauka, Saint-Petersburg, 415 pp. (in Russian)

Khak, V.A., 2003a. Technological abrasion-accumulation and eolation impact in the near-shore area of Bratsk water reservoir, $Z$ badan nad wplywem antropopresji na srodowisko, 2 , Sosnowiec, 22-27 (in Russian)

Khak, V.A., 2003b. The role of wind conditions in the development of eolation in the shore of Verkhneangarsk area of the Bratsk water reservoir, Geology of resources and resource development problems, Trudy VII International Symposium in the name of Acad. M.A. Usov, Tomsk Polytechnic University Press, Tomsk, 215-216. (in Russian) 
Khak, V.A., Kozyreva, E.A., and Maksimishina, Yu.S., 2005. Some details of evolution of the shores of the Angara reservoirs, Srodowisko przyrodnicze wobec zagrozen antropogenicznych, Sosnowiec, 67-80. (in Russian)

Logatchev, N.A., Lomonosova, T.K., and Klimanova, V.M., 1964. Cenozoic sediments of the Irkutsk pit, Nauka, Moscow, 193 pp. (in Russian)

Ovchinnikov, G.I., 1998. Some regular trends of wind and wave drifting on emerged shoals and shorefaces of the Bratsk water reservoir, Wspolczesne procesy eoliczne, WnoZ US, SGP, Sosnowiec, 61-72. (in Russian)

Ovchinnikov, G.I., Pavlov, S.Kh., and Trzhtsinsky, Yu.B., 1999. Change of geological environment in the Angaro-Yenisei reservoir-affected areas, Nauka, Novosibursk, 254 pp. (in Russian)

Vika, S., Ovchinnikov, G.I., Trzhtsinsky, Yu.B., Tyts, A., and Shipek, T., 2000. Natural processes on the shores of Bratsk water reservoir, IEC SB RAS, Irkutsk, 71 pp. (in Russian)

Zenkovich, V.P., 1962. The elements of science of seacoast evolution, Izd-vo Akad. Nauk, Moscow, 710 pp. (in Russian) 